\title{
Assessing the Role of Corticothalamic and Thalamo- Accumbens Projections in the Augmentation of Heroin Seeking in Chronically Food-Restricted Rats
}

\author{
Alexandra Chisholm, Damaris Rizzo, Émilie Fortin, Vanessa Moman, Nour Quteishat, Assunta Romano, \\ Tanya Capolicchio, and ${ }^{\circ}$ Uri Shalev \\ Department of Psychology, Center for Studies in Behavioral Neurobiology, Concordia University, Montreal, Quebec H4B 1R6, Canada
}

Drug addiction is a chronic disorder characterized by compulsive drug seeking, and involves repetitive cycles of compulsive drug use, abstinence, and relapse. In both human and animal models of addiction, chronic food restriction increases rates of relapse. Our laboratory has reported a robust increase in drug seeking following a period of withdrawal in chronically foodrestricted rats compared with sated controls. Recently, we reported that activation of the paraventricular nucleus of the thalamus (PVT) abolished heroin seeking in chronically food-restricted rats. However, the precise inputs and outputs of the PVT that mediate this effect remain elusive. The goal of the current study was to determine the role of corticothalamic and thalamo-accumbens projections in the augmentation of heroin seeking induced by chronic food restriction. Male Long-Evans rats were trained to self-administer heroin for $10 \mathrm{~d}$. Next, rats were removed from the self-administration chambers and were subjected to a $14 \mathrm{~d}$ withdrawal period while sated (unlimited access to food) or mildly food-restricted (FDR). On day 14, rats were returned to the self-administration context for a $3 \mathrm{~h}$ heroin-seeking test under extinction conditions during which corticothalamic and thalamo-accumbens neural activity was altered using chemogenetics. Surprisingly, chemogenetic activation or inhibition of corticothalamic projections did not alter heroin-seeking behavior. Chemogenetic activation of thalamo-accumbens shell, but not core, projectors attenuated heroin seeking in FDR rats. The results indicate an important role for the PVT to nucleus accumbens shell projections in the augmentation of heroin seeking induced by chronic food restriction.

Key words: abstinence; addiction; DREADD; relapse; self-administration

Significance Statement

Relapse to heroin use is one of the major obstacles in the treatment of opiate addiction. Triggers for relapse are modulated by environmental challenges such as caloric restriction. Elucidating the brain mechanisms that underlie relapse is critical for evidence-based treatment development. Here we demonstrate a critical role for the input from the paraventricular thalamus (PVT), a hub for cortical, sensory, and limbic information, to the nucleus accumbens shell (an area known to be important for reward and motivation) in the augmentation of heroin seeking in food-restricted rats. Our findings highlight a previously unknown role for the PVT in heroin seeking following a period of abstinence.

\section{Introduction}

Drug addiction is a chronic disorder characterized by compulsive drug seeking and cycling among periods of drug use, abstinence, and relapse (O’Brien, 1997). In abstinent drug users, relapse is

\footnotetext{
Received Aug. 17, 2020; revised Nov. 9, 2020; accepted Nov. 15, 2020

Author contributions: A.C. and U.S. designed research; A.C., D.R., E.F., V.M., N.Q., A.R., and T.C. performed research; A.C., A.R., and U.S. analyzed data; A.C. and U.S. edited the paper.

This work was supported by the Natural Sciences and Engineering Council (NSERC) Discovery Program (Grant 6694-2016; to U.S.). A.C. was supported by NSERC. We thank Dr. Chris Law for ImageJ macro development.

The authors declare no competing financial interests.

Correspondence should be addressed to Uri Shalev at uri.shalev@concordia.ca.

https://doi.org/10.1523/JNEUROSCI.2103-20.2020

Copyright $\odot 2021$ the authors
}

triggered by the following three main factors: (1) re-exposure to drugs of abuse, (2) re-exposure to drug-associated cues, and (3) stressors (Childress et al., 1993; De Wit, 1996; Sinha, 2001). Caloric restriction modulates these triggers, resulting in increased use of alcohol, coffee and tobacco, subjective drug craving, and rates of relapse (Franklin et al., 1948; Hall et al., 1992; Krahn et al., 1992; Pirie et al., 1992; Cheskin et al., 2005).

In animal models of relapse, acute and chronic caloric restriction can alter drug-related behavior. Restricted food intake increases the initiation of drug use and maintenance of drug intake (Carroll and Meisch, 1984). Acute food deprivation (24-48 h) and chronic food restriction reinstate extinguished drug seeking (Shalev et al., 2001, 2003; Shalev, 2012). We also observed a robust increase in heroin seeking 
in chronically food-restricted rats following a withdrawal period (D'Cunha et al., 2013; Sedki et al., 2013). More recently, we have demonstrated a critical role for the metabolic hormones ghrelin and leptin in the ventral tegmental area (D'Cunha et al., 2020), and for dopamine transmission in the nucleus accumbens (NAc) in food restriction-induced augmentation of heroin seeking (D'Cunha et al., 2017). However, the neural circuitry that underlies the impact of food restriction on drug seeking has not been entirely elucidated.

The paraventricular nucleus of the thalamus (PVT) is a midline thalamic nucleus that is uniquely located to integrate subcortical and cortical information related to motivational, emotional, and homeostatic states to guide behavior (Kirouac, 2015; Millan et al., 2017; Zhou and Zhu, 2019), including drug addiction. The PVT receives dense innervation from medial prefrontal cortex (mPFC) glutamatergic projections that arise from the prelimbic ( $\mathrm{PrL}$ ), infralimbic, and insular cortices ( $\mathrm{Li}$ and Kirouac, 2012). The major projections from the PVT target the NAc core (NAcC) and NAc shell (NAcS) subregions, but appear to preferentially target the medial aspect of the NAcS (Millan et al., 2017). A considerable proportion of the PVT to NAc efferents collateralize to innervate the bed nucleus of stria terminalis (BNST) and central amygdala (CeA; Dong et al., 2017).

The PVT connections mentioned above (mPFC, NAc, BNST, CeA) are critical components of drug seeking and relapse circuitry (Tang et al., 2015; Reiner et al., 2019). Accordingly, PVT is selectively activated during ethanol and cocaine seeking, and inactivation of the posterior PVT (pPVT) blocked cue-induced reinstatement of cocaine seeking (Matzeu et al., 2014, 2015). Inhibition of PrL-pPVT projecting neurons immediately following the last cocaine self-administration session attenuated postabstinence context-induced cocaine seeking and cue-induced reinstatement of extinguished cocaine seeking (Giannotti et al., 2018). Interestingly, Otis et al. (2019) recently described a functional innervation of PVT-NAc neurons by mPFC input, demonstrating a role for this circuit in responses to reward-associated cues.

Currently, there is limited knowledge on the role of the PVT in opioid drug taking and seeking. We recently reported that activation of the PVT attenuated heroin seeking in chronically food-restricted rats, suggesting that the PVT is critically involved in the augmentation of heroin seeking (Chisholm et al., 2020). Our findings agree with the report that stimulation of the excitatory input from the PrL to the PVT attenuated the incentive value of food-paired cues, specifically in rats that attribute incentive salience to reward-associated cues (sign trackers; Campus et al., 2019). However, it is not easy to reconcile our findings with the attenuation of drug seeking following inhibition of the PVT or the PrL-PVT pathway, as described above. Thus, understanding the precise function and circuitry of the PVT involved in drug seeking remains a major challenge.

The objective of this study was to investigate the role of PrLPVT and PVT-NAc projections in the augmentation of heroin seeking induced by chronic food restriction. We used chemogenetics in a projection-specific manner to excite or inhibit the PrL-PVT, PVT-NAcS, and PVT-NAcC pathways.

\section{Materials and Methods}

Subjects

Male Long-Evans rats, weighing 250-275 g at the beginning of the experiments, were used in four different experiments. Before surgery, rats were pair housed for 1 week under a reverse $12 \mathrm{~h}$ light/dark cycle (lights OFF at 9:30 A.M.) with unrestricted access to chow (Agribran
Purina Canada) and water, unless otherwise specified. Following surgery, rats were individually housed in plastic shoebox cages for $2 \mathrm{~d}$ before being moved to the operant conditioning chambers for drug self-administration. Following drug self-administration training, rats were returned to the animal care facility and individually housed for the drug withdrawal phase. All experiments were approved by the Animal Research Ethics Committee of Concordia University and were conducted in accordance with the recommendations of the Canadian Council on Animal Care.

\section{Intravenous and intracranial surgery}

Before surgery, rats were subcutaneously administered $2 \mathrm{ml}$ of $0.9 \%$ saline, penicillin (450 $000 \mathrm{IU} / \mathrm{rat}$, s.c.), and atropine $(0.1 \mathrm{mg} / \mathrm{kg} / \mathrm{rat})$ to aid in hydration and prevent infection, followed by the analgesic ketoprofen $(2.0 \mathrm{mg} / \mathrm{kg}$; Merial Canada) postoperatively. Under $2 \%$ isoflurane anesthesia, rats were implanted with an intravenous SILASTIC catheter (Dow Corning) into the right jugular vein, as previously described (Sedki et al., 2013). Immediately following intravenous catheterization, rats were intracranially injected with $0.75 \mu \mathrm{l}$ of a viral vector [Canadian Neurophotonic Platform (Viral Vector Core team)] at a rate of $0.1 \mu \mathrm{l} /$ min and implanted with single (PVT) or bilateral (NAc) guide cannulae (23 gauge; Plastics One) as detailed below. One of the more elegant aspects of the chemogenetic approach is the ability to manipulate local neuronal excitability using systemic administration of the designer receptor exclusively activated by designer drugs (DREADD) ligand. However, to allow for pathway specificity and to avoid an effect on other areas because of collateralization (Dong et al., 2017), here we opted to administer clozapine- $N$-oxide (CNO; a DREADD ligand) locally at the areas of interest. The general viral vector approach and time line for each experiment are presented in Figure 1.

Experiment 1. Chemogenetic activation of PrL-PVT projections was as follows: AAV8-hSyn-hM3D(Gq)-mCherry was bilaterally injected into the PrL [anteroposterior (AP), +3.0; mediolateral (ML) 1.0; dorsoventral (DV), -3.5]; and a guide cannula aimed at the PVT (AP, -3.0; ML, 0.0; DV, -3.2 ; relative to bregma) was implanted (Fig. $1 A$ ).

Experiment 2. Chemogenetic inhibition of PrL-PVT projections was as follows: AAV8-hSyn-hM4D(Gi)-mCherry was bilaterally injected into the PrL; and a guide cannula aimed at the PVT was implanted (Fig. 1B).

Experiment 3A. Chemogenetic excitation of PVT-NAcS projections was as follows: AAV8-hSyn-hM3D(Gq)-mCherry was injected into the PVT (AP, -3.0 ; ML, 0.0; DV, -5.4 ; relative to bregma); and guide cannulae were aimed at the NAcS (AP, +1.70; ML, $\pm 3.70 ; \mathrm{DV},-4.60 ; 20^{\circ}$ angle; relative to bregma) were implanted (Fig. 1C).

Experiment $3 B$. Specificity of the $\mathrm{CNO}$ effect in rats expressing mCherry control DREADDs in PVT-NAcS projections was as follows: AAV8-hSyn-mCherry was injected into the PVT; and guide cannulae aimed at the NAcS were implanted (Fig. 1D).

Experiment 4. Chemogenetic excitation of PVT-NAcC projections was as follows: AAV8-hSyn-hM3D(Gq)-mCherry was injected into the PVT; and guide cannulae aimed at the NAcC (AP, +2.52; ML, \pm 2.50 ; DV,$-4.50 ; 6^{\circ}$ angle; relative to bregma) were implanted (Fig. $1 E$ ).

\section{Apparatus}

Operant conditioning chambers (Coulbourn Instruments; $29.0 \times 29.0 \times$ $25.5 \mathrm{~cm}$ ) enclosed in sound-attenuating boxes were used. Each chamber was equipped with a red house light, a food hopper, and a water bottle. The "active" lever was positioned $9 \mathrm{~cm}$ above the floor and was located on the wall opposite the house light. An "inactive" lever was positioned $9 \mathrm{~cm}$ above the floor, on the same wall of as the active lever. Responses on the active lever activated an infusion pump (Razel Scientific Instruments). A white cue light and tone generator $(2.9 \mathrm{kHz}$; Sonalert, Coulborn Instruments) were located directly above the active lever. Presses on the inactive lever were recorded but had no programmed consequence. The infusion pump was connected to the catheter through a liquid swivel (Lomir Biomedical) and Tygon tubing (Saint-Gobain) shielded with a metal spring.

\section{Drugs}

Heroin $\mathrm{HCl}$ (contribution from the National Institute on Drug Abuse) was dissolved in $0.9 \%$ sterile saline. CNO (contribution from the 
National Institute on Drug Abuse) was dissolved in $1 \%$ DMSO (Thermo Fisher Scientific) in $0.9 \%$ sterile saline. CNO was injected using a $10 \mu \mathrm{l}$ Hamilton syringe and a microinfusion pump (Harvard Apparatus), through a 28 gauge injector (Plastics One) that extended $2 \mathrm{~mm}$ below the guide cannulae (rate, $0.30 \mu \mathrm{l} / \mathrm{min}$ ). The injector was left in place for $2 \mathrm{~min}$ following the infusion to allow for optimal drug diffusion. A $1 \%$ DMSO solution in saline was used as a vehicle (veh) control.

\section{Heroin self-administration}

Following a $24 \mathrm{~h}$ habituation period to the operant chamber, rats were trained to selfadminister heroin for $10 \mathrm{~d}$, with three $3 \mathrm{~h}$ sessions/d separated by $3 \mathrm{~h}$ intervals, under a fixed interval $20 \mathrm{~s}$ schedule of reinforcement. The first daily session began shortly after the onset of the lights OFF period and was signaled by the illumination of the house light, entry of the active lever, and activation of the cue light and the tone for $30 \mathrm{~s}$ or until the active lever was pressed. Responses on the active lever resulted in a $0.1 \mathrm{mg} / \mathrm{kg}$ infusion of heroin over $12 \mathrm{~s}$ and the initiation of a $20 \mathrm{~s}$ timeout period during which the house light was turned off, and the cue light and tone were activated. Responses made on the active lever during the timeout were recorded but did not result in an additional infusion.

\section{Drug withdrawal}

Following heroin self-administration training, all rats were removed from their operant chamber and placed in the animal colony in individual plastic shoebox cages for $24 \mathrm{~h}$ of drug washout. During this $24 \mathrm{~h}$ period, all rats had unrestricted access to food and water. Following drug washout, rats were assigned to one of two groups matched for the average number of infusions taken, active lever responses made, and body weight over the last $5 \mathrm{~d}$ of training [food-restricted (FDR) or sated (unrestricted access to food)]. During the $14 \mathrm{~d}$ withdrawal period, the amount of food given to restricted rats was titrated to maintain the rats at $90 \%$ of their drug washout day body weight.

\section{Heroin-seeking test}

On the 14th day of food restriction, rats were returned to the operant conditioning chambers for one $3 \mathrm{~h}$ heroin-seeking test session. Rats were intracranially injected with either $0.30 \mu \mathrm{l}$ of CNO (1 mm) or $0.30 \mu \mathrm{l}$ of vehicle $10 \mathrm{~min}$ before the beginning of the heroinseeking testing. During testing, all conditions were identical to self-administration training except that rats were tested under extinction conditions. At the time of the test, all rats had a minimum of 5 weeks of viral incubation.

\section{Locomotor activity test}

To assess possible nonspecific motor effects of the chemogenetic manipulations, on the 16th day of food restriction, rats were intracranially injected with either $0.30 \mu \mathrm{l}$ of $\mathrm{CNO}(1 \mathrm{~mm})$ or $0.30 \mu \mathrm{l}$ of vehicle $10 \mathrm{~min}$ before the beginning of a locomotor activity test. Locomotor activity data were collected using the TRU SCAN 2.0 Activity Monitoring System (Coulbourn

B

C

D

E line for experiment 4.

\section{A Exp 1: Chemogenetic Excitation of PrL-PVT Projections}
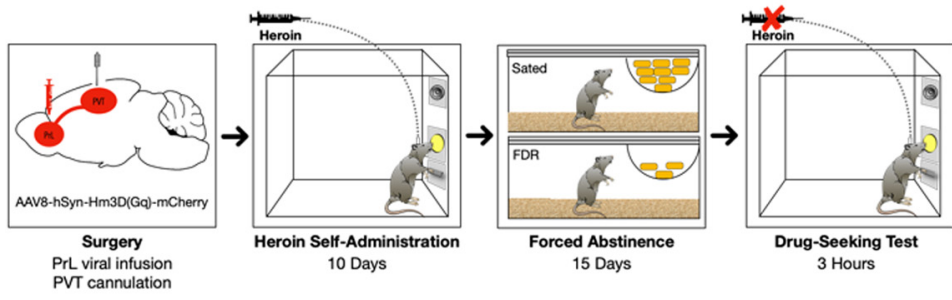

Exp 2: Chemogenetic Inhibition of PrL-PVT Projections
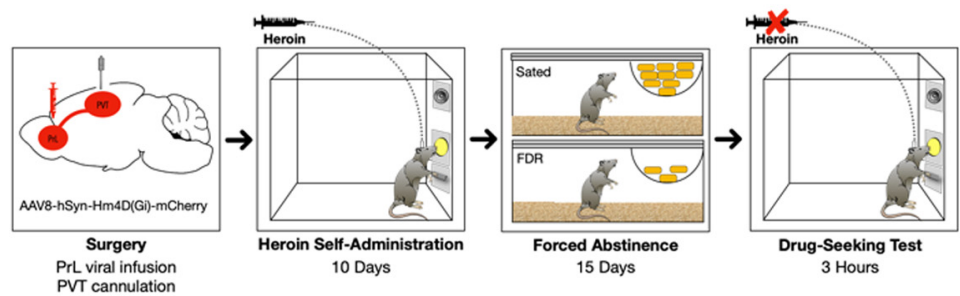

15 Days

3 Hours

Exp 3A: Chemogenetic Excitation of PVT-NAcS Projections
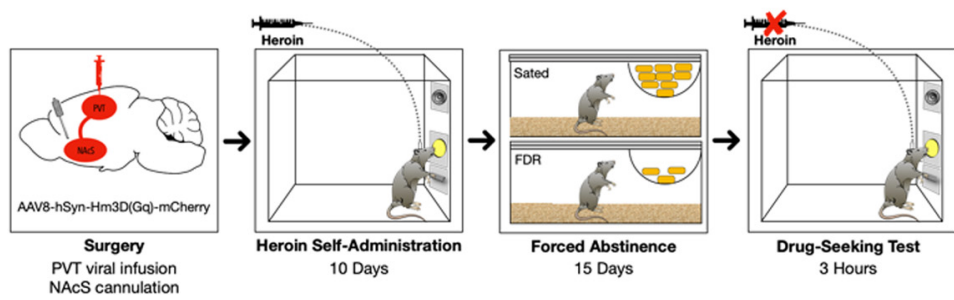

Exp 3B: CNO Effect in Rats Expressing DREADDs in PVT-NAcS Projections
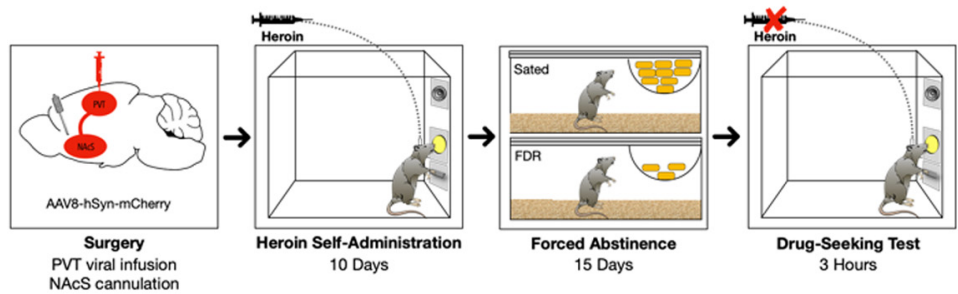

Exp 4: Chemogenetic Excitation of PVT-NAcC Projections
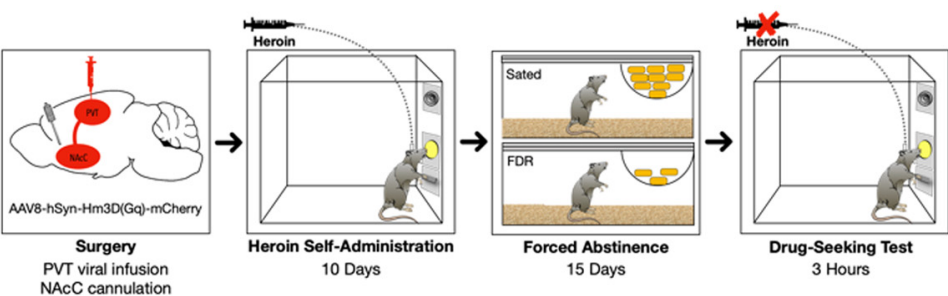

Figure 1. Diagram of viral vector approach and general experimental time lines. $\boldsymbol{A}$, Diagram of viral vector approach and the experimental time line for experiment 1. B, Diagram of viral vector approach and the experimental time line for experiment 2. C, Diagram of viral vector approach and the experimental time line for experiment 3A. D, Diagram of viral vector approach and the experimental time line for experiment $3 B$. $E$, Diagram of viral vector approach and the experimental time

Instruments). The total distance covered (in centimeters) was recorded for $1 \mathrm{~h}$.

\section{Validation of DREADD functionality}

Rats that underwent behavioral testing were used to assess DREADD functionality in PrL-PVT projection inhibition (experiment 2) and PVT-NAcC projection activation (experiment 4). Because of technical 
issues with brain collection, two new groups of 12 rats were used to validate DREADD functionality in PrL-PVT projection activation (experiment 1 ) and PVT-NAcS projection activation (experiment 3 ).

Fos immunohistochemistry

Rats were intracranially infused with $\mathrm{CNO}(1 \mathrm{~mm})$ or vehicle, and 90 min later were overdosed with sodium pentobarbital and transcardially perfused with $\mathrm{PBS}, \mathrm{pH} 7.4$, followed by $4 \%$ paraformaldehyde. Brains were extracted and postfixed in $4 \%$ paraformaldehyde for $24 \mathrm{~h}$, followed by cryoprotection in a $30 \%$ sucrose solution at $4^{\circ} \mathrm{C}$ for $48 \mathrm{~h}$. Brain tissue was collected in $40 \mu \mathrm{m}$ coronal slices using a Leica cryostat and stored at $-20^{\circ} \mathrm{C}$ in cryoprotectant. Free-floating sections containing the PVT were washed $12 \times 5 \mathrm{~min}$ in TBS. Sections were blocked in $3 \%$ normal goat serum and $0.20 \%$ Triton $\mathrm{X}$ in TBS for $2 \mathrm{~h}$ at $4^{\circ} \mathrm{C}$. Sections were then incubated for $48 \mathrm{~h}$ at $4^{\circ} \mathrm{C}$ with the primary rabbit anti-Fos antibody (1:2000; catalog \#2250S, Cell Signaling Technology) in 3\% normal goat serum and $0.15 \%$ Triton X in TBS. Next, sections were washed $5 \times 5$ min with TBS and then quenched in a $0.3 \%$ TBS hydrogen peroxide for $30 \mathrm{~min}$ at $4^{\circ} \mathrm{C}$. Sections were washed $5 \times 5 \mathrm{~min}$ and were then incubated in the secondary antibody solution containing biotinylated goat anti-rabbit IgG antibody (1:200; Vector Laboratories), 3\% normal goat serum, and $0.2 \%$ Triton $\mathrm{X}$ at $4^{\circ} \mathrm{C}$. Following secondary incubation, sections were washed $3 \times 5 \mathrm{~min}$ in TBS and were then incubated for $1 \mathrm{~h}$ in a Vectastain Elite $\mathrm{ABC}$ solution (Vector Laboratories) at $4^{\circ} \mathrm{C}$. Sections were washed $3 \times 5 \mathrm{~min}$ in TBS, and then Fos-reactive cells were visualized by reacting with $\mathrm{DAB}$ and Nickle $\mathrm{Cl}$ (Vector Laboratories) for $1.5 \mathrm{~min}$. The reaction was stopped by placing the sections in tap water for $5 \mathrm{~min}$. Sections were washed $3 \times 5$ in TBS and mounted onto SuperFrost Plus microscope slides, and coverslipped with Permount medium (Thermo Fisher Scientific). Injection placement and viral expression were determined under a confocal microscope (model DMRA2, Leica) using the TX2 filter with reference to the brain atlas of Paxinos and Watson (2005) as previously described (Chisholm et al., 2020).

Fos immunoreactivity quantification

Fos immunoreactivity (IR) quantification was conducted by an experimenter blind to conditions. Images were taken using the software program ToupView (Hangzhou ToupTek Photonics) that was connected to a ToupTek LCMOS (low-voltage complementary metal oxide semiconductor) digital camera and a Leica microscope (model DM4000). ImageJ software (National Institutes of Health) was used for Fos-labeled cell counting. In experiments 1 and 2, one image per section was taken with a $20 \times$ objective. Three images from the PVT (AP, -2.76 to -3.48 , relative to bregma) with the highest number of Fos-reactive cells were averaged for each subject. In experiments 3 and 4 , in each brain section, for each hemisphere, two images were captured with a $20 \times$ objective. For each subject, counts from three bilateral sections from the NAc shell (AP, 1.68-1.92, relative to bregma) or core (AP, 2.28-2.76, relative to bregma) with the highest number of Fos-reactive cells were averaged.

\section{Statistical analyses}

The critical threshold for statistically significant results was set at $p<0.05$. Body weights were compared using $t$ tests, corrected for unequal variance when necessary. In experiments $1,2,3 \mathrm{~A}$, and 4 , the total number of active and inactive lever responses made during the heroin-seeking test was analyzed using two separate two-way ANOVAs with drug treatment (vehicle; $\mathrm{CNO}$ ) and feeding condition (FDR, sated) as between-subjects factors and planned comparisons.

The number of active lever responses made over time during the heroin-seeking tests was analyzed using a three-way ANOVA with drug treatment (vehicle; $\mathrm{CNO}$ ) and feeding condition (FDR, sated) as between-subjects factors and time $(3 \times 1 \mathrm{~h}$ segments $)$ as the within-subjects factor. Significant interactions were analyzed using three separate two-way ANOVAs with drug treatment (vehicle; $\mathrm{CNO}$ ) and feeding condition (FDR, sated) as factors at hour 1, hour 2, and hour 3 of the heroin-seeking test. The number of Fos-immunoreactive cells in CNO and vehicle-treated subjects were compared using $t$ tests, corrected for unequal variance when necessary.
Table 1. Mean \pm SEM number of active lever responses, inactive lever responses, and heroin infusions made on the last day of training $(9 \mathrm{~h})$, and body weight on test day in experiment 1

\begin{tabular}{llccl}
\hline & Infusions & Active lever & Inactive lever & Body weight $(\mathrm{g})$ \\
\hline Sated-vehicle & $28.57 \pm 2.52$ & $89.29 \pm 25.17$ & $8.14 \pm 2.84$ & $435.29 \pm 11.53^{*}$ \\
Sated-CNO & $35.00 \pm 3.07$ & $94.90 \pm 10.54$ & $9.00 \pm 2.99$ & $420.90 \pm 11.98^{*}$ \\
FDR-vehicle & $32.63 \pm 5.75$ & $73.25 \pm 20.41$ & $6.13 \pm 2.14$ & $352.63 \pm 9.21$ \\
FDR-CNO & $39.88 \pm 5.32$ & $111.88 \pm 28.65$ & $25.38 \pm 21.85$ & $341.00 \pm 5.58$ \\
\hline
\end{tabular}

$* p<0.0001$, Sated compared with FDR rats.

Table 2. Mean \pm SEM number of active lever responses, inactive lever responses, and heroin infusions made on the last day of training $(9 \mathrm{~h})$, and body weight on test day in experiment 2

\begin{tabular}{lllrl}
\hline & Infusions & Active lever & Inactive lever & Body weight $(\mathrm{g})$ \\
\hline Sated-vehicle & $38.88 \pm 5.88$ & $111.00 \pm 30.70$ & $14.13 \pm 4.37$ & $521.13 \pm 13.89^{*}$ \\
Sated-CN0 & $46.24 \pm 5.24$ & $126.89 \pm 24.86$ & $17.00 \pm 4.32$ & $518.56 \pm 13.94^{*}$ \\
FDR-vehicle & $47.48 \pm 8.66$ & $161.62 \pm 48.18$ & $9.82 \pm 2.83$ & $399.40 \pm 10.06$ \\
FDR-CN0 & $54.64 \pm 5.35$ & $138.73 \pm 22.06$ & $19.18 \pm 7.66$ & $397.27 \pm 8.33$ \\
\hline
\end{tabular}

$* p<0.0001$, Sated compared with FDR rats.

In experiment $3 \mathrm{~B}$, the number of active and inactive lever responses made during the heroin-seeking test were analyzed using two separate $t$ tests with feeding condition (FDR, sated) as a between-subjects factor. The number of active lever responses made over time during the heroinseeking test was analyzed using a two-way ANOVA with feeding condition (FDR, sated) as the between-subjects factor and time $(3 \times 1 \mathrm{~h}$ segments) as the within-subjects factor. Post hoc analyses were applied where necessary using the Bonferroni correction.

\section{Results}

There were no statistically significant differences in the acquisition of heroin self-administration between the different experimental groups during the last $5 \mathrm{~d}$ of self-administration training for any experiment. The mean \pm SEM number of infusions, active lever responses, and inactive lever response made on the last day of heroin self-administration training for each experiment are shown in Tables 1, 2, 3, 4, and 5.

\section{Experiment 1: activation of PrL-PVT projections did not change food restriction-induced augmentation of heroin seeking}

Twenty-two rats were removed because of catheter leakage, failure to train, health issues, incorrect viral vector placement/ expression, or incorrect injector placement. One rat (Sated-CNO group) was considered an outlier because of an extreme number of active lever presses performed during the test $(>2.5$ SDs above group average). Therefore, the final analysis included 33 rats in the following four experimental conditions: FDR-vehicle $(n=8)$, FDR-CNO $(n=8)$, sated-vehicle $(n=7)$, and sated-CNO $(n=10)$. On test day, FDR rats $(n=16$; weight, $346.81 \pm 5.42 \mathrm{~g})$ weighed statistically significantly less than sated rats $(n=17 ; 426.82 \pm 8.43$ g; $\left.t_{(31)}=7.874, p<0.0001, d=2.83\right)$.

As expected, food-restricted rats pressed more on the active lever during the heroin-seeking test, when compared with their sated counterparts (feeding condition: $F_{(1,29)}=12.32, p=0.002, \eta^{2}=0.29$; Fig. $2 A$ ). However, no statistically significant effects for $\mathrm{CNO}$ treatment $\left(F_{(1,29)}=1.11, p=0.301, \eta^{2}=0.03\right)$ or feeding condition $\times$ CNO treatment interaction $\left(F_{(1,29)}=0.72, p=0.402, \eta^{2}=0.02\right)$ were found. No statistically significant effects were found for inactive lever responding. Analysis of active lever responding over the test session ( $1 \mathrm{~h}$ bins) revealed statistically significant effects of time $\left(F_{(1.362,39.49)}=71.43, p<0.001, \eta^{2}=0.39\right)$, feeding condition 
Table 3. Mean \pm SEM number of active lever responses, inactive lever response and heroin infusions made on the last day of training (9 h), and body weight on test day in experiment $3 \mathrm{~A}$

\begin{tabular}{lllll}
\hline & Infusions & Active lever & Inactive lever & Body weight $(\mathrm{g})$ \\
\hline Sated-vehicle & $44.78 \pm 4.76$ & $133.44 \pm 27.15$ & $27.67 \pm 8.77$ & $446.56 \pm 13.43^{*}$ \\
Sated-CN0 & $49.63 \pm 9.08$ & $144.50 \pm 47.64$ & $16.00 \pm 5.45$ & $446.13 \pm 17.03^{*}$ \\
FDR-vehicle & $53.50 \pm 6.49$ & $162.75 \pm 36.49$ & $13.75 \pm 2.50$ & $344.25 \pm 8.54$ \\
FDR-CN0 & $48.00 \pm 11.41$ & $150.43 \pm 56.80$ & $11.43 \pm 4.47$ & $340.71 \pm 9.60$ \\
\hline
\end{tabular}

$* p<0.0001$, Sated compared with FDR rats.

Table 4. Mean \pm SEM number of active lever responses, inactive lever responses, and heroin infusions made on the last day of training (9 h), and body weight on test day in experiment 3B

\begin{tabular}{lllll}
\hline & Infusions & Active lever & Inactive lever & Body weight $(\mathrm{g})$ \\
\hline Sated-CN0 & $56.43 \pm 13.24$ & $181.43 \pm 63.57$ & $24.71 \pm 10.64$ & $442.86 \pm 10.27^{*}$ \\
FDR-CN0 & $53.14 \pm 10.38$ & $146.43 \pm 49.65$ & $10.57 \pm 2.40$ & $314.43 \pm 11.57$ \\
\hline
\end{tabular}

$* p<0.0001$, Sated compared with FDR rats.

Table 5. Mean \pm SEM number of active lever responses, inactive lever responses, and heroin infusions made on the last day of training $(9 \mathrm{~h})$, and body weight on test day in experiment 4

\begin{tabular}{lllll}
\hline & Infusions & Active lever & Inactive lever & Body weight $(\mathrm{g})$ \\
\hline Sated-vehicle & $45.63 \pm 8.63$ & $133.63 \pm 39.60$ & $19.63 \pm 4.70$ & $445.88 \pm 25.52^{*}$ \\
Sated-CNO & $39.20 \pm 9.15$ & $126.90 \pm 43.74$ & $14.30 \pm 5.44$ & $432.90 \pm 22.74^{*}$ \\
FDR-vehicle & $42.30 \pm 11.60$ & $117.70 \pm 47.04$ & $24.60 \pm 7.49$ & $330.70 \pm 15.77$ \\
FDR-CN0 & $46.55 \pm 5.67$ & $107.91 \pm 21.21$ & $9.73 \pm 3.90$ & $385.55 \pm 19.51$ \\
\hline
\end{tabular}

$* p<0.0001$, Sated compared with FDR rats.

$\left(F_{(1,29)}=12.32, p=0.002, \eta^{2}=0.33\right)$, time $\times$ feeding condition interaction $\left(F_{(2,58)}=5.00, p=0.010, \eta^{2}=0.03\right)$, and time $\times$ feeding condition $\times \mathrm{CNO}$ treatment interaction $\left(F_{(2,58)}=4.64, p=0.014\right.$, $\left.\eta^{2}=0.03\right)$. However, no statistically significant effects for $\mathrm{CNO}$ treatment $\left(F_{(1,29)}=1.11, p=0.301, \eta^{2}=0.03\right)$, time $\times$ CNO treatment interaction $\left(F_{(2,58)}=2.64, p=0.078, \eta^{2}=0.01\right)$, or feeding condition $\times \mathrm{CNO}$ treatment interaction $\left(F_{(1,29)}=0.72, p=0.402\right.$, $\left.\eta^{2}=0.02\right)$ were found. Post hoc two-way ANOVAs revealed a statistically significant main effect of feeding condition at each time point, indicating that food-restricted rats displayed higher levels of responding at hour $1\left(F_{(1,29)}=11.16, p=0.002, \eta^{2}=0.25\right)$, hour 2 $\left(F_{(1,29)}=10.40, p=0.003, \eta^{2}=0.26\right)$, and hour $3\left(F_{(1,29)}=12.13\right.$, $\left.p=0.002, \eta^{2}=0.29\right)$ compared with sated rats (Fig. $2 B$ ). No other statistically significant main effects or interactions were observed.

\section{Locomotor test}

Data from the locomotor activity test were lost for one animal in the Sated-CNO group. The mean \pm SEM distances traveled (in centimeters) were as follows: Sated-Vehicle group, 7266.53 \pm 363.18; Sated-CNO group, 6406.17 \pm 810.16 ; FDR-Vehicle group, $6570.35 \pm 1191.36$; and FDR-CNO group, 6571.64 \pm 980.48 . No statistically significant effects were observed for distance traveled.

\section{Validation of DREADD functionality}

CNO treatment $(n=6)$ statistically significantly increased the number of Fos-IR cells in the PVT rats compared with vehicle controls $\left(n=6 ; t_{(10)}=1.85, p=0.047, d=1.17\right.$; Fig. $\left.2 C\right)$, indicating that DREADD-mediated excitation of the PrL-PVT pathway successfully increased neuronal activity in the PVT. Representative DREADD expression in the terminal region of the PrL-PVT projection neurons is presented in Figure $2 A$.
Experiment 2: Inhibition of PrL-PVT projections did not change food restriction-induced augmentation of heroin seeking Ten rats were removed because of catheter leakage, failure to train, health issues, incorrect viral vector placement/expression, or incorrect injector placement. Two rats (Sated-Veh and FDRVeh groups) were considered outliers because of an extreme number of active lever presses performed during the test $(>2.5$ SDs above group average). Therefore, the final analysis included 38 rats in the following four experimental conditions: FDR-vehicle $(n=10)$; FDR-CNO $(n=11)$; sated-vehicle $(n=8)$; and satedCNO $(n=9)$. On test day, FDR rats $(n=21$; weight, $398.29 \pm$ $6.32 \mathrm{~g})$ weighed statistically significantly less than sated rats $(n=17$; weight, $519.76 \pm 9.55 \mathrm{~g}, t_{(36)}=10.96, p<0.0001, d=3.65$ ).

Food restriction augmented heroin seeking as indicated by the high number of active lever responses when compared with sated controls (feeding condition: $F_{(1,34)}=20.82, p<0.0001$, $\eta^{2}=0.36$; Fig. $3 A$ ). However, no statistically significant effects for CNO treatment $\left(F_{(1,34)}=2.20, p=0.147, \eta^{2}=0.04\right)$ or feeding condition $\times \mathrm{CNO}$ treatment interaction $\left(F_{(1,34)}=0.03\right.$, $p=0.853, \eta^{2}=0.00$ ) were found indicating that inhibition of PrL-PVT projections did not alter heroin seeking regardless of the feeding condition. There were no significant effects for inactive lever responding. Analysis of active lever responding over the test session ( $1 \mathrm{~h}$ bins; Fig. $3 B$ ) revealed statistically significant effects of time $\left(F_{(1.336,45.43)}=64.08, p<0.0001, \eta^{2}=0.41\right)$, feeding condition $\left(F_{(1,34)}=20.80, p<0.0001, \eta^{2}=0.30\right)$, and time $\times$ feeding condition interaction $\left(F_{(2,68)}=8.09, p=0.001, \eta^{2}=\right.$ $0.05)$. However, no statistically significant effects for CNO treatment $\left(F_{(1,34)}=2.14, p=0.153, \eta^{2}=0.03\right)$, time $\times$ CNO treatment interaction $\left(F_{(2,68)}=0.14, p=0.871, \eta^{2}=0.00\right)$, feeding condition $\times$ CNO treatment interaction $\left(F_{(1,34)}=0.03, p=0.866, \eta^{2}=0.00\right)$, or time $\times$ feeding condition $\times$ CNO treatment interaction $\left(F_{(2,68)}=\right.$ $0.14, p=0.869, \eta^{2}=0.00$ ) were found. Post hoc two-way ANOVAs revealed a statistically significant main effect of feeding condition in each time point indicating that food-restricted rats displayed higher levels of responding at hour $1\left(F_{(1,34)}=16.23, p<0.001, \eta^{2}=0.32\right)$, hour $2\left(F_{(1,34)}=23.39, p<0.001, \eta^{2}=0.38\right)$, and hour $3\left(F_{(1,34)}=\right.$ $\left.11.65, p=0.002, \eta^{2}=0.24\right)$ compared with sated rats. No other statistically significant main effects or interactions were observed.

\section{Locomotor activity test}

Data from the locomotor activity test were lost for one animal in the Sated-Vehicle group. The mean \pm SEM distances traveled (in centimeters) were as follows: Sated-Vehicle group, $6855.91 \pm 563.59$; Sated-CNO group, 6282.86 \pm 327.21; FDR-Vehicle group, $5756.77 \pm 789.03$; and FDRCNO group, 7302.05 \pm 723.92 . No statistically significant effects were observed for distance traveled.

\section{Validation of DREADD functionality}

CNO treatment $(n=6)$ statistically significantly reduced the number of Fos-IR cells in the posterior PVT compared with vehicle controls $\left(n=6 ; t_{(10)}=2.06, p=0.033, d=1.31\right)$ indicating that DREADD-mediated inhibition of the PrL-PVT pathway successfully decreased neuronal activity in the PVT (Fig. 3C). Representative DREADD expression in the PrL and in the terminal region of the PrL-PVT projection neurons is presented in Figure $3 A$.

Experiment 3A: Excitation of PVT-NAcS pathway blocked food restriction-induced augmentation of heroin seeking Eighteen rats were removed because of catheter leakage, failure to train, health issues, incorrect viral vector placement, 

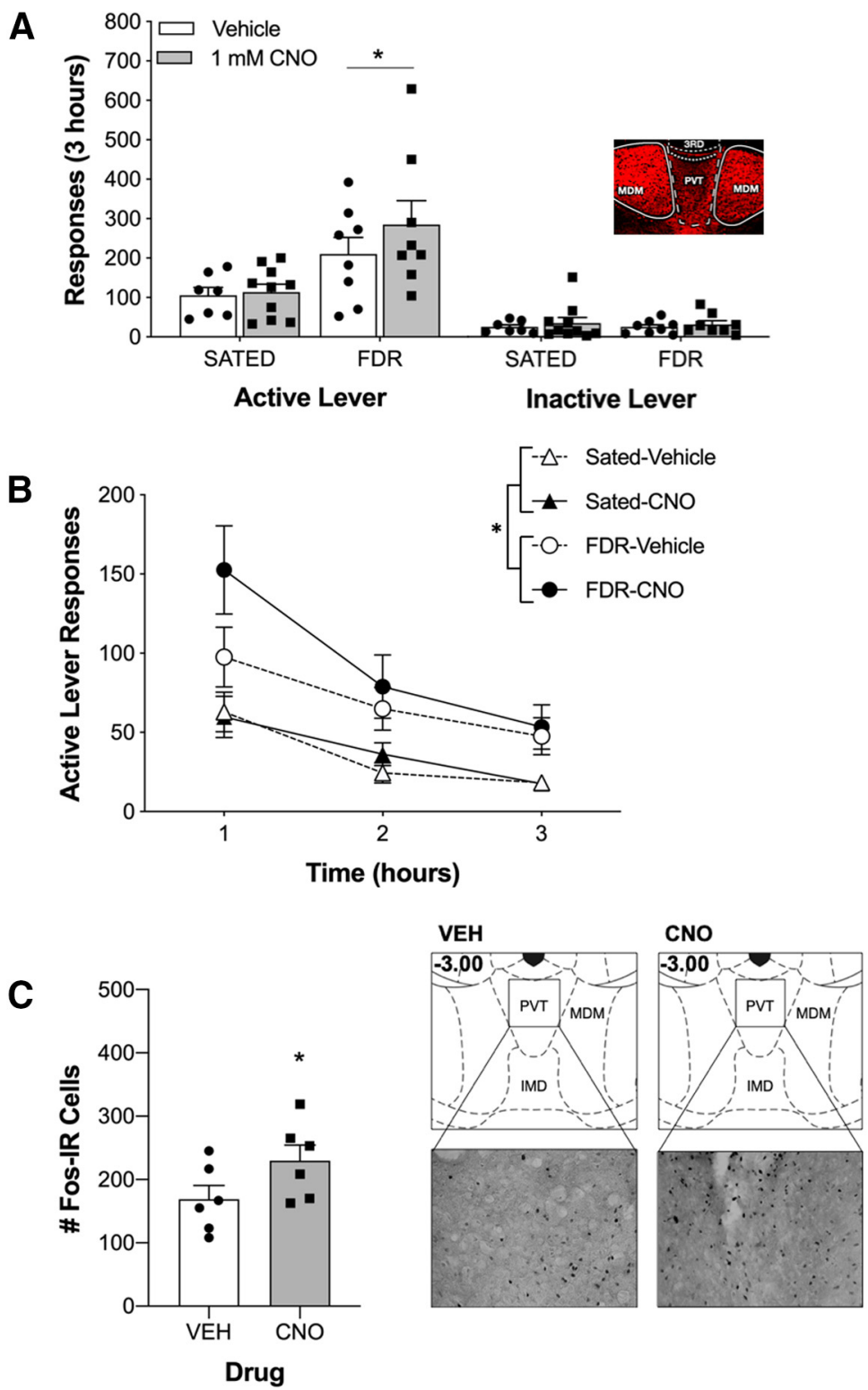

Figure 2. Chemogenetic activation of PrL-PVT projections did not alter food restriction-induced augmentation of heroin seeking. Rats were intracranially administered CNO (1 mM) or vehicle into the PVT 5-10 min before the test. $A$, Mean \pm SEM number of active (left) and inactive (right) lever responses made during the $3 \mathrm{~h}$ heroin-seeking test on day 14 of food restriction in the Sated and FDR groups. $* p<0.01$, compared with Sated groups. Insert, Representative section of mCherry-tagged immunofluorescence in PrL-PVT projections in the terminal region taken with $5 \times$ objective (relative to bregma, +3.00 ). $\boldsymbol{B}$, Mean \pm SEM number of active lever responses made over the $3 \mathrm{~h}$ test, presented in $1 \mathrm{~h}$ time intervals. $* p<0.01$, compared with Sated groups. $C$, Chemogenetic activation of PrL-PVT projections increased the number of Fos-IR cells in the PVT of CNO-treated subjects compared with vehicle. Rats were intracranially administered CNO (1 mM) or vehicle into the PVT 90 min before the perfusion. Data are the mean \pm SEM number of Fos-IR cells in the PVT of vehicle- and CNO-treated rats who had their PrL-PVT projections activated (left). $* p<0.05$, vehicle compared with CNO treatment. Example Fos-IR in the PVT in vehicle- and CNO-treated subjects are also presented (right). All images were taken with $20 \times$ objective.

sated rats $(n=17$; weight, $446.35 \pm$ $10.37 \mathrm{~g} ; t_{(30)}=8.31, p<0.0001, d=$ $3.04)$.

Chemogenetic excitation of the PVTNAcS pathway in the FDR group, but not in the Sated group, resulted in a dramatic attenuation of active lever responses compared with vehicle-treated rats (Fig. 4A). Two-way ANOVA revealed a statistically significant main effect of CNO treatment $\left(F_{(1,28)}=5.71, p=\right.$ $\left.0.024, \eta^{2}=0.14\right)$. No statistically significant effects of feeding condition $\left(F_{(1,28)}=3.48, p=0.073, \eta^{2}=0.09\right)$ or $\mathrm{CNO}$ treatment $\times$ feeding condition $\left(F_{(1,28)}=2.92, p=0.098, \eta^{2}=0.07\right)$ interaction were found. Planned comparisons revealed a statistically significant difference between FDR-vehicle and sated-vehicle rats $(p=0.014 ; d=$ 1.06), and this effect was reversed by CNO treatment (FDR-vehicle vs FDRCNO: $p=0.009, d=0.99)$. No statistically significant main effects or interaction were found for inactive lever responding during the heroin-seeking test.

Analysis of active lever responding over the test session ( $1 \mathrm{~h}$ bins) revealed a statistically significant main effect of time $\left(F_{(1.165,32.61)}=36.37, p<0.0001, \eta^{2}=\right.$ $0.34)$ and CNO treatment $\left(F_{(1,28)}=5.71\right.$, $p=0.024, \eta^{2}=0.16$; Fig. $\left.4 B\right)$. However, no statistically significant effects for feeding condition $\left(F_{(1,28)}=3.48, p=0.073\right.$, $\left.\eta^{2}=0.10\right)$, time $\times$ feeding condition $\left(F_{(2,56)}=2.65, p=0.08, \eta^{2}=0.02\right)$, time $\times$ CNO treatment interaction $\left(F_{(2,56)}=\right.$ 2.41, $\left.p=0.099, \eta^{2}=0.02\right)$, feeding condition $\times$ CNO treatment interaction $\left(F_{(1,28}\right.$ $\left.=2.92, p=0.098, \eta^{2}=0.08\right)$, or time $\times$ feeding condition $\times \mathrm{CNO}$ treatment interaction $\left(F_{(2,56)}=2.17, p=0.124, \eta^{2}=\right.$ 0.02 ) were found. Visual inspection of active lever responses made over the test session indicates that the response rate of the FDR-CNO group was consistently low from the outset of the heroin-seeking test session when compared with the FDR-Vehicle group.

\section{Locomotor activity}

Data from the locomotor activity test were lost for one animal in the Sated$\mathrm{CNO}$ group. The mean \pm SEM distances

or incorrect injector placement. One rat (FDR-CNO) was considered an outlier because of an extreme number of active lever presses performed during the test $(>2.5$ SDs above group average). Therefore, the final analysis included 32 rats in the following four experimental conditions: FDRvehicle $(n=8)$; FDR-CNO $(n=7)$; sated-vehicle $(n=9)$; and sated-CNO $(n=8)$. On test day, FDR rats $(n=15$; weight, $342.60 \pm 6.17 \mathrm{~g})$ weighed statistically significantly less than traveled (in centimeters) were as follows: Sated-Vehicle group, 6038.10 \pm 769.51; Sated-CNO group, $5387.84 \pm 603.44$; FDR-Vehicle group, $8829.25 \pm 538.85$; and FDR-CNO group, $9954.77 \pm 1090.33$. Food restriction statistically significantly increased the total distance traveled compared with sated rats (feeding condition: $\left.F_{(1,27)}=22.57, p<0.0001, \eta^{2}=0.44\right)$. No statistically significant effect of $\mathrm{CNO}$ treatment or feeding condition $\times \mathrm{CNO}$ 
treatment interaction was observed during the $1 \mathrm{~h}$ locomotor activity test.

Validation of DREADD functionality CNO treatment $(n=5)$ statistically significantly increased the number of FosIR cells in the NAcS compared with vehicle controls $\left(n=6 ; t_{(9)}=2.09\right.$, $p=0.033, d=1.39$; Fig. $4 C$ ), indicating that DREADD-mediated excitation of the PVT-NAcS pathway successfully increased neuronal activity in the NAcS. Representative DREADD expression in the terminal region of the PVT-NAcS projection neurons is presented in Figure $4 A$.

\section{Experiment 3B: CNO infusion did} not change heroin seeking in rats expressing an mCherry control virus in PVT-NAcS projections

Six rats were removed because of catheter leakage, failure to train, excessive training, health issues, incorrect viral vector placement, or incorrect guide cannula placement. Therefore, the final analysis included 14 rats in the following two experimental conditions: FDR-CNO $(n=7)$ and sated-CNO $(n=7)$. On test day, FDR rats $(n=7$; weight, $314.43 \pm$ $11.57 \mathrm{~g}$ ) weighed statistically significantly less than sated rats $(n=7$; weight, $442.86 \pm 10.27 \mathrm{~g} ; t_{(12)}=8.31, p<0.0001$, $d=4.80)$.

On test day, FDR rats made statistically significantly more responses on the active lever than sated rats $\left(t_{(12)}=\right.$ 3.01, $p=0.011, d=1.73$; Fig. $5 A$ ). No statistically significant differences in inactive lever responding during the test were observed. Notably, heroin seeking in the sated and FDR groups was similar to the levels observed in experiment $3 \mathrm{~A}$. Analysis of active lever responding over the test session ( $1 \mathrm{~h}$ bins) revealed statistically significant main effects of time $\left(F_{(1.582,18.99)}=43.66, p<0.0001, \eta^{2}=\right.$ $0.54)$ and feeding condition $\left(F_{(1,12)}=\right.$ 9.03, $\left.p=0.011, \quad \eta^{2}=0.24\right)$, and a time $\times$ feeding condition interaction $\left(F_{(2,24)}=6.07, p=0.007, \eta^{2}=0.08\right)$. Post hoc analyses revealed that FDR rats pressed statistically significantly more on the active lever at hour $1(p=0.03$,

$d=2.46$ ) when compared with sated rats (Fig. $5 B$ ). These data indicate that the infusion of CNO in the absence of an active DREADD did not alter heroin seeking in chronically food-restricted rats.

Data from the locomotor activity test was lost for two rats in the FDR group and one animal in the sated group. The mean \pm SEM distances traveled (in centimeters) were as follows: Sated-CNO group, $6504.60 \pm 496.51$; FDR-CNO group, $4587.52 \pm 975.37$. No statistically significant effects were observed for locomotor activity.
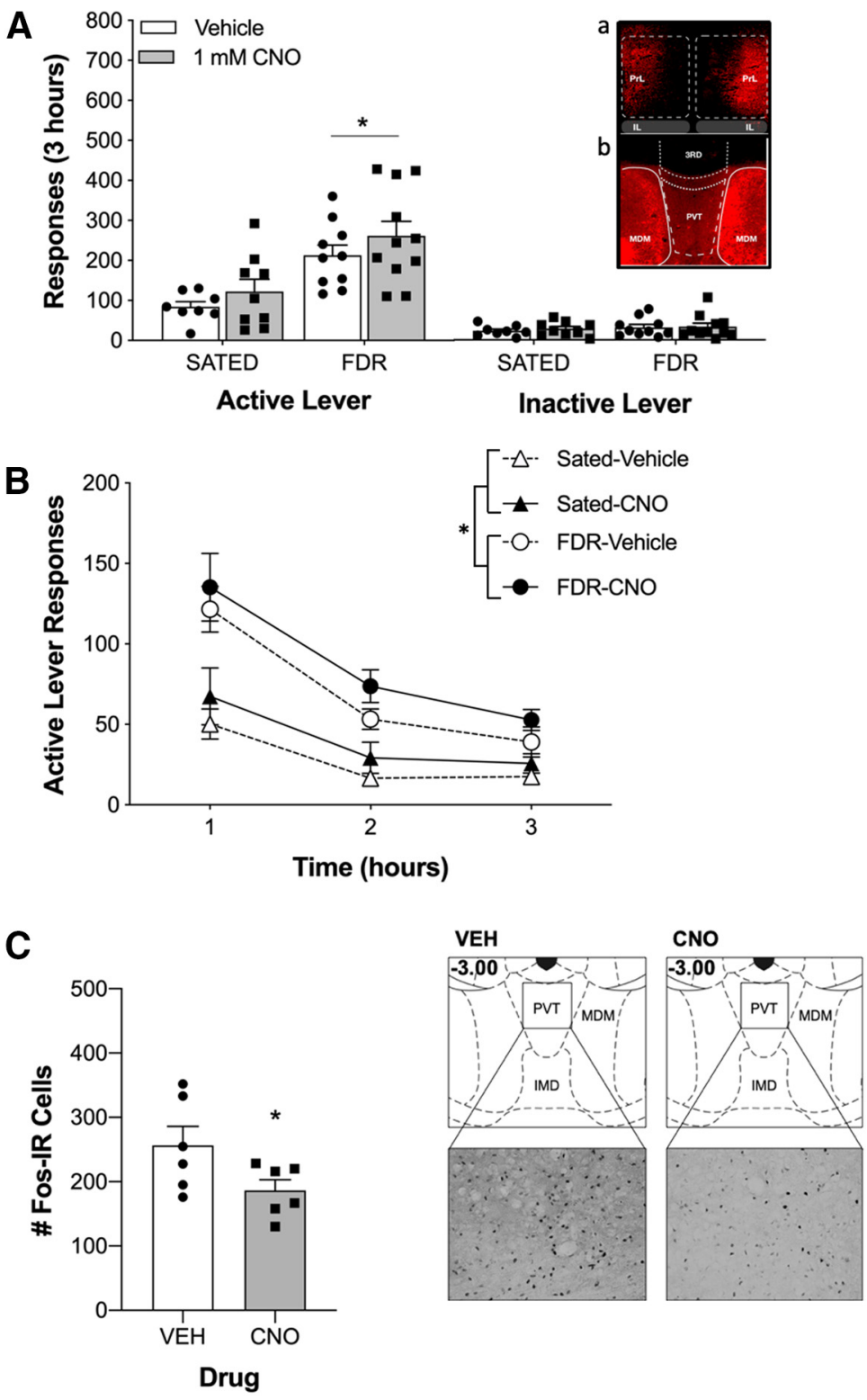

Figure 3. Chemogenetic inhibition of PrL-PVT projections did not alter food restriction-induced augmentation of heroin seeking. Rats were intracranially administered CNO (1 mm) or vehicle into the PVT 5-10 min before the test. $\boldsymbol{A}$, Mean \pm SEM number of active (left) and inactive (right) lever responses made during the $3 \mathrm{~h}$ heroin-seeking test on day 14 of food restriction in the Sated and FDR groups. $* p<0.0001$, compared with Sated groups. Insert: $\boldsymbol{a}$, Representative section of mCherry tagged immunofluorescence in PrL cell bodies (relative to bregma, +3.00 ) taken with a $2.5 \times$ objective. $\boldsymbol{b}$, Representative section of mCherry-tagged immunofluorescence in PrL-PVT projections in the terminal region taken with a $5 \times$ objective. $\boldsymbol{B}$, Mean \pm SEM number of active lever responses made over the $3 \mathrm{~h}$ test, presented in $1 \mathrm{~h}$ time intervals. $* p<0.01$, FDR compared with Sated groups. C, Chemogenetic inhibition of PrL-PVT projections reduced the number of Fos-IR cells in the PVT of CNO-treated subjects compared with vehicle. Rats were intracranially administered CNO (1 mm) or vehicle into the PVT 90 min before the perfusion. Data are Mean \pm SEM number of Fos-IR cells in the PVT of vehicle- and CN0-treated rats who had their PrL-PVT projections inhibited (left). $* p<0.05$, vehicle compared with CNO treatment. Example Fos-IR in the PVT of vehicleand CNO-treated subjects are also presented (right). All images were taken with a $20 \times$ objective.

Experiment 4: Excitation of PVT-NAcC pathway did not change food restriction-induced augmentation of heroin seeking

Eleven rats were removed because of catheter leakage, failure to train, health issues, incorrect viral vector placement, or incorrect injector placement. The final analysis included 39 rats in the following four experimental conditions: FDR-vehicle $(n=10)$; FDR-CNO $(n=11)$; sated-vehicle $(n=8)$; and satedCNO $(n=10)$. On test day, FDR rats $(n=21$; weight, $345.29 \pm 12.76 \mathrm{~g})$ weighed statistically significantly less than 


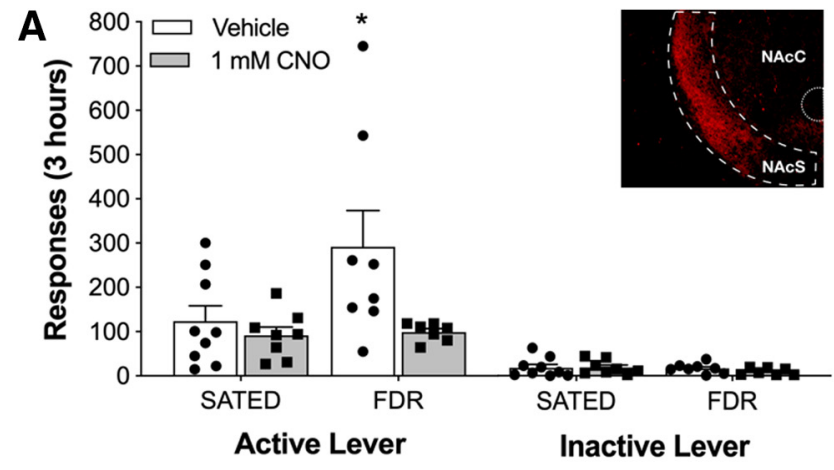

B
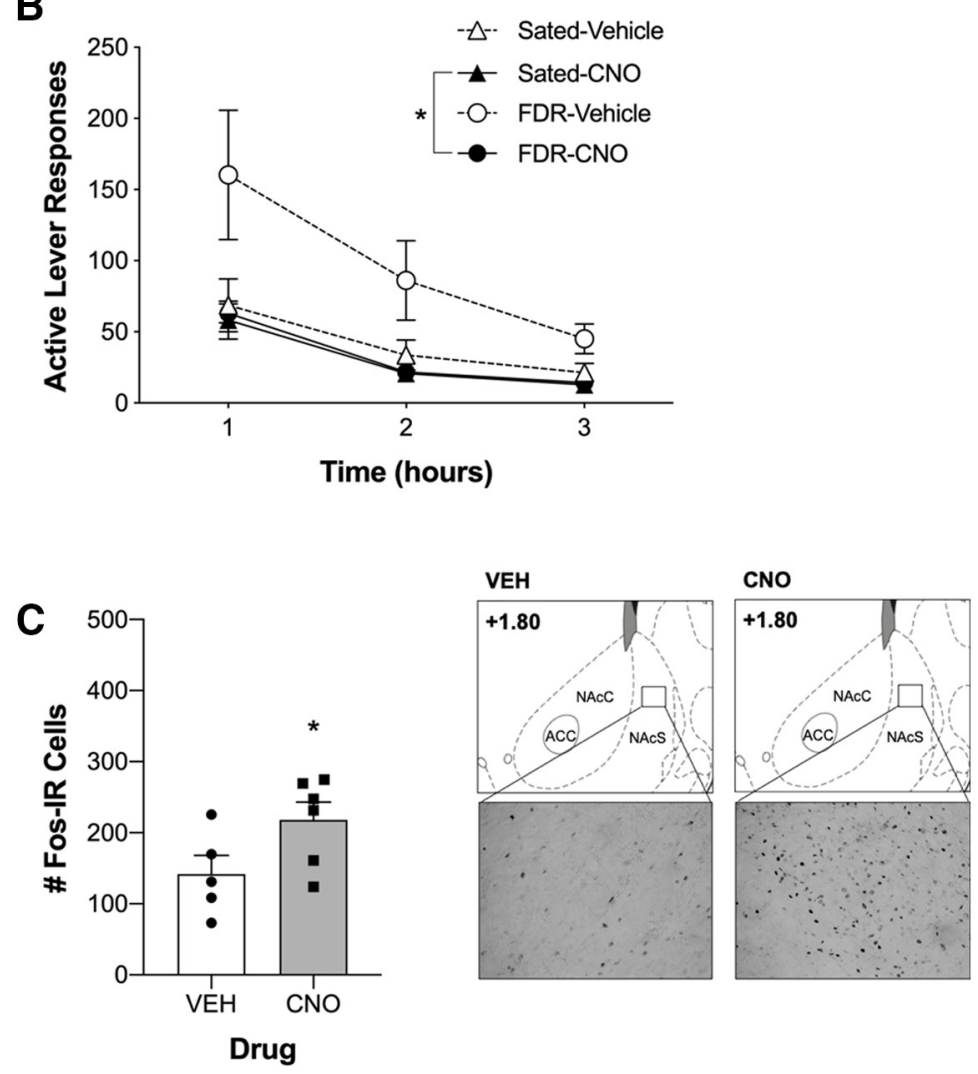

Figure 4. Chemogenetic activation of PVT-NACS projections blocked food restriction-induced augmentation of heroin seeking. Rats were intracranially administered CNO (1 mM) or vehicle into the NACS 5-10 min before the test. $\boldsymbol{A}$, Mean \pm SEM number of active (left) and inactive (right) lever responses made during the $3 \mathrm{~h}$ heroin-seeking test on day 14 of food restriction in the Sated and FDR groups. $* p<0.05$, compared with sated vehicle and FDR CNO groups. Insert, Representative section of mCherry-tagged immunofluorescence in PVT-NACS projections in the terminal region taken with a $10 \times$ objective. $\boldsymbol{B}$, Mean \pm SEM number of active lever responses made over the $3 \mathrm{~h}$ test, presented in $1 \mathrm{~h}$ time intervals. $* p<0.05$, CNO compared with vehicle-treated groups. C, Chemogenetic activation of PVT-NACS projections increased the number of Fos-IR cells in the NACS of CNO-treated rats compared with vehicle-treated rats. Rats were intracranially administered CNO (1 mM) or vehicle into the NACS 90 min before the perfusion. Data are the mean \pm SEM number of Fos-IR cells in the NACS of vehicle- and CNO-treated rats who had their PVT-NAc shell projections activated (left). $* p<0.05$, vehicle compared with CNO treatment. Example Fos-IR in the NACS of vehicle- and CNO-treated subjects are also presented (right). All images were taken with a $20 \times$ objective.

sated rats $\left(n=18\right.$; weight, $438.67 \pm 16.54 \mathrm{~g} ; t_{(37)}=4.54, p<$ $0.001, d=1.49)$.

Food-restricted rats pressed significantly more on the active lever during the heroin-seeking test, compared with the sated group (feeding condition: $F_{(1,35)}=23.03, p<0.0001, \eta^{2}=0.39$; Fig. 6A). No statistically significant effects of CNO treatment $\left(F_{(1,35)}=0.46, p=0.502, \eta^{2}=0.01\right)$ or CNO treatment $\times$ feeding condition interaction $\left(F_{(1,35)}=0.024, p=0.877, \eta^{2}=0.00\right)$ were found. Post hoc analyses revealed that FDR-vehicle- and FDR-CNO-treated subjects displayed elevated levels of responding on the active lever compared with Sated-vehicle and Sated-CNO subjects. These results indicate that chemogenetic excitation of the PVT-NAcC pathway did not attenuate heroin seeking in chronically food-restricted rats. A significant interaction (feeding condition $\times$ CNO treatment: $\left.F_{(1,35)}=6.18, p=0.018, \eta^{2}=0.15\right)$ was observed for inactive lever responding. However, post hoc tests revealed no statistically significant differences between the groups.

Analysis of active lever responding over the test session ( $1 \mathrm{~h}$ bins) revealed statistically significant main effects of time $\left(F_{(1.183,41.40)}=64.68, p<0.0001, \eta^{2}=\right.$ $0.40)$ and feeding condition $\left(F_{(1,35)}=\right.$ 24.11, $\left.p<0.0001, \eta^{2}=0.28\right)$, and a time $\times$ feeding condition interaction $\left(F_{(2,70)}=\right.$ 13.38, $p<0.0001, \eta^{2}=0.08$; Fig. 6B). Post $h o c$ analyses revealed that FDR rats pressed statistically significantly more on the active lever at hour $1\left(F_{(1,35)}=22.27, p<0.0001\right.$, $\left.\eta^{2}=0.39\right)$, hour $2\left(F_{(1,35)}=14.68, p=0.001\right.$, $\left.\eta^{2}=0.28\right)$, and hour $3\left(F_{(1,35)}=20.43\right.$, $\left.p<0.0001, \eta^{2}=0.36\right)$ when compared with sated rats, indicating that FDR rats were slower to extinguish their responding during the heroin-seeking test.

\section{Locomotor activity}

The mean \pm SEM distances traveled (in centimeters) were as follows: SatedVehicle group, 6270.73 \pm 583.83 ; SatedCNO group, $4794.58 \pm 359.83$; FDR-Vehicle group, $7204.42 \pm 703.78$; and FDR-CNO group, 7163.25 \pm 955.27 . Food restriction statistically significantly increased the distance traveled (feeding condition: $F_{(1,35)}=$ 5.22, $p=0.029, \eta^{2}=0.12$ ). No statistically significant effect of $\mathrm{CNO}$ treatment or feeding condition $\times \mathrm{CNO}$ treatment interaction was observed during the $1 \mathrm{~h}$ locomotor activity test.

\section{Validation of DREADD functionality}

CNO treatment $(n=6)$ statistically significantly increased Fos protein expression in the NAc core when compared with vehicle controls $\left(n=6 ; t_{(10)}=1.92, p=0.042\right.$, $d=1.22$; Fig. $6 C$ ). Representative DREADD expression in the terminal region of the PVT-NAcC projection neurons is presented in Figure $6 A$.

\section{Discussion}

We examined the role of corticothalamic and thalamo-accumbens projections in the augmentation of heroin seeking in chronically food-restricted rats following a period of withdrawal by chemogenetically manipulating these projections imme- 
A

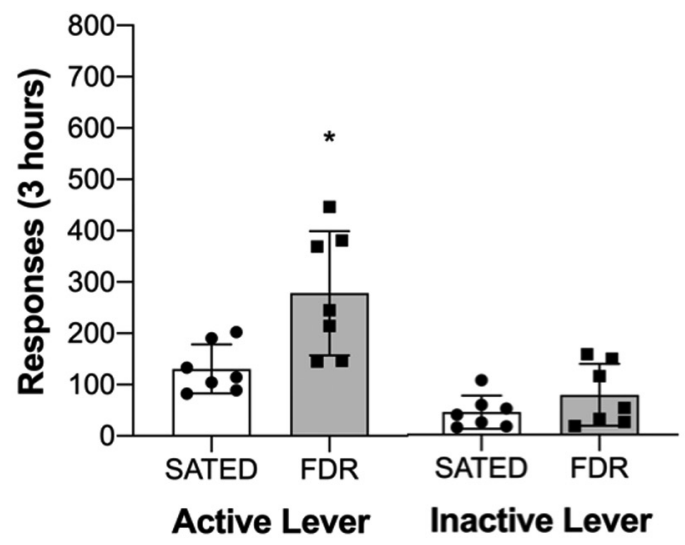

B

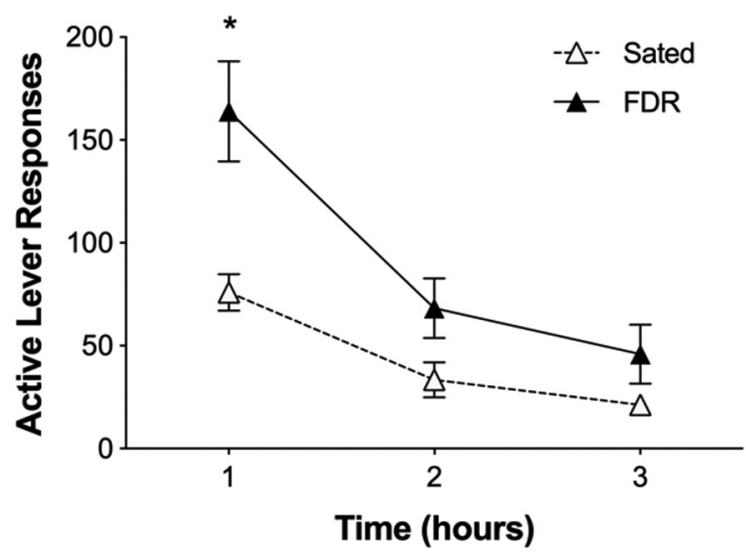

Figure 5. CNO infusion in PVT-NACS projections expressing only mCherry did not alter food restriction-induced augmentation of heroin seeking. Rats were intracranially administered CNO (1 mM) into the NACS 5-10 min before the test. $\boldsymbol{A}$, Mean \pm SEM number of active (left) and inactive (right) lever responses made during the $3 \mathrm{~h}$ heroin-seeking test on day 14 of food restriction in the Sated and FDR groups. $* p<0.05$, compared with the Sated group. $B$, Mean \pm SEM number of active lever responses made over the $3 \mathrm{~h}$ test, presented in $1 \mathrm{~h}$ time intervals. $* p<0.05$ compared with the Sated group.

diately before a heroin-seeking test. To our knowledge, this is the first study to examine the role of corticothalamic and thalamo-accumbens projections in heroin seeking. As previously reported, chronically food-restricted rats displayed a robust increase in heroin seeking compared with sated controls (D’Cunha et al., 2013, 2017; Sedki et al., 2013, 2015; Chisholm et al., 2020). Contrary to our initial hypotheses, chemogenetic activation or inhibition of PrL-PVT projections did not alter heroin seeking in our chronically food-restricted rats. In agreement with our initial hypothesis, chemogenetic activation of PVT-NAcS projections, but not PVT-NAcC projections, blocked the augmentation of heroin seeking in the chronically food-restricted rats.

Activation or inhibition of the PrL-PVT pathway did not change food restriction-induced augmentation of heroin seeking

The role of the PrL-PVT pathway in reward seeking is ambiguous. Exposure to reward-associated cues appears to result in an inhibitory response in PrL-PVT neurons, and activation of this pathway suppressed the acquisition and expression of conditioned reward seeking (Otis et al., 2019). In contrast, the inhibition of the PrL-PVT pathway attenuated cue-induced cocaine seeking (Giannotti et al., 2018). Consequently, we explored the effects of PrL-PVT projection inhibition and excitation. PrLPVT projections arising from layer VI reportedly participate in fear learning, drug seeking, the attribution of incentive salience to reward-associated cues, and cue reward learning (Otis et al., 2017, 2019; Giannotti et al., 2018; Campus et al., 2019). Thus, the lack of effect for PrL-PVT projection manipulations on heroin seeking in our chronically food-restricted rats is surprising.

Food restriction can increase the incentive value of rewardpaired cues (Anderson et al., 2013). Unpublished data from our laboratory indicate that food restriction increases the incentive value of heroin-associated cues in second-order conditioning and choice procedures (Sedki et al., 2015; Society for Neuroscience Annual Meeting abstract). Nonselective inhibition of the PVT resulted in a robust increase in cue-induced reinstatement of cocaine seeking in rats that attribute predictive value to reward cues (goal trackers), suggesting that the PVT inhibits cue-triggered drug seeking (Kuhn et al., 2018). The same group reported that chemogenetic inhibition of PrL-PVT projections enhanced the incentive value of reward-paired cues in goal trackers, while activation of PrL-PVT projections decreased the incentive value in rats that attribute motivational value to reward cues (sign trackers; Campus et al., 2019). Accordingly, we hypothesized that activation of PrL-PVT projections would reduce the incentive value of the heroin-associated cue in our chronically food-restricted rats leading to dampened heroin seeking. However, we did not prescreen our rats to identify individual differences in incentive salience attribution to cues. Thus, one possible reason for the lack of an effect for PrL-PVT manipulations is that the different effects in sign trackers and goal trackers blurred the overall effect.

Although the input from the PrL to the PVT plays a major role in response to reward-associated cues (Otis et al., 2017), including relapse to cocaine seeking (Giannotti et al., 2018), other excitatory and inhibitory inputs integrate with cortical input to control behavior (Otis et al., 2019). We believe that GABAergic input from the zona incerta (ZI) or lateral hypothalamus (LHA) may play a role in the augmentation of heroin seeking induced by chronic food restriction. Activation of the ZIPVT pathway elicits a strong feeding response (Zhang and van den Pol, 2017). Additionally, the ZI-PVT pathway is activated in response to food deprivation and by grehlin, an orexigenic hormone, suggesting that the ZI-PVT pathway is sensitive to the effects of caloric restriction (Zhang and van den Pol, 2017). Furthermore, a dense input from the hypothalamus to the PVT carries inhibitory GABAergic and peptidergic signals implicated in arousal, feeding, energy homeostasis, and stress responses, which are likely conveyed in PVT-NAcS projections (Millan et al., 2017; Otis et al., 2019). Future studies will investigate whether inhibition of the ZI-PVT or LHA-PVT pathway will attenuate the augmentation of heroin seeking in our chronically food-restricted rats.

Activation of projections from the PVT to the NAcS, but not $\mathrm{NAcC}$, blocked food restriction-induced augmentation of heroin seeking

The attenuation of food restriction-induced augmentation of heroin seeking observed following PVT-NAcS pathway activation agrees with our previous report that chemogenetic activation of the PVT blocked heroin seeking in food-restricted rats (Chisholm et al., 2020). Our findings align with the idea presented by Kuhn et al. (2018) that the PVT output inhibits cueinduced drug (and probably non-drug reward) seeking through 
A

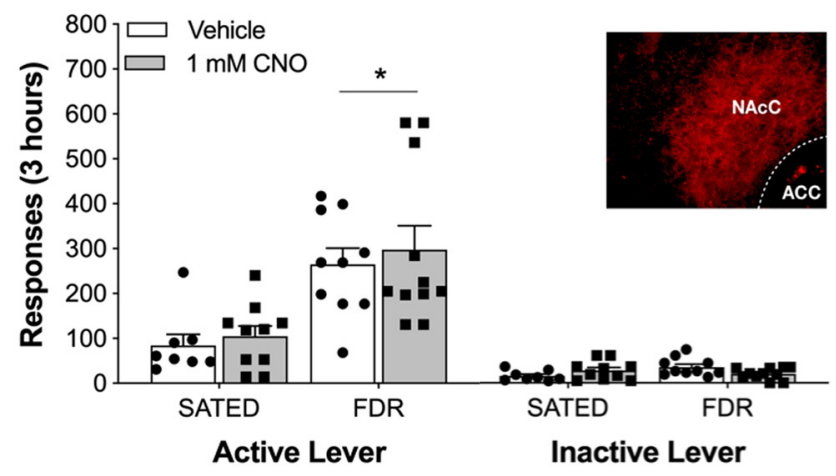

B

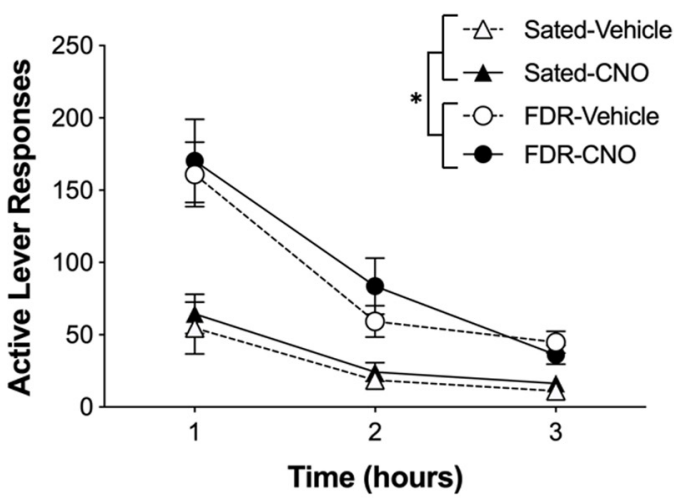

C
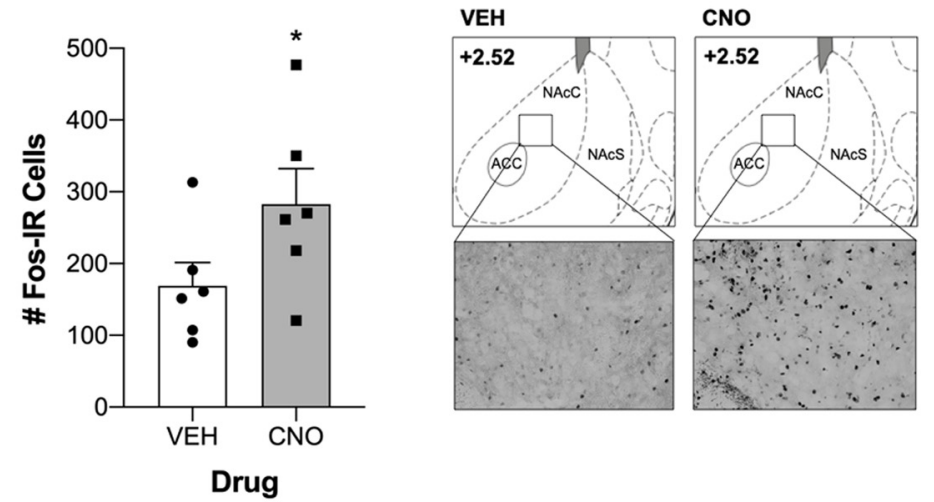

Figure 6. Chemogenetic activation of PVT-NACC projections did not alter food restriction-induced augmentation of heroin seeking. Rats were intracranially administered CNO (1 mM) or vehicle into the NACC 5-10 min before the test. $\boldsymbol{A}$, Mean \pm SEM number of active (left) and inactive (right) lever responses made during the $3 \mathrm{~h}$ heroin-seeking test on day 14 of food restriction in the Sated and FDR groups. $* p<0.0001$, compared with Sated groups. Insert, Representative section of $\mathrm{mCherry-tagged} \mathrm{immunofluorescence} \mathrm{in} \mathrm{PVT-NACC} \mathrm{projections} \mathrm{in} \mathrm{the} \mathrm{terminal} \mathrm{region} \mathrm{taken} \mathrm{with} \mathrm{a} 20 \times$ objective. $\boldsymbol{B}$, Mean \pm SEM number of active lever responses made over the $3 \mathrm{~h}$ test, presented in $1 \mathrm{~h}$ time intervals. $* p<0.001$, FDR compared with Sated groups. C, Chemogenetic activation of PVT-NAcC projections increased the number of Fos-IR cells in the NACC of CNO-treated rats compared with vehicle-treated rats. Rats were intracranially administered CNO $(1 \mathrm{~mm})$ or vehicle into the NACC 90 min before the perfusion. Mean \pm SEM number of Fos-IR cells in vehicle- and in CNO-treated rats who had their PVT-NACC projections activated (left). $* p<0.05$, vehicle compared with CNO treatment. Example Fos-IR in the NAcC of vehicle- and CNO-treated subjects are also presented (right). All images were taken with a $20 \times$ objective.

attenuation of the incentive value of the cues. Accordingly, photoactivation of PVT-NAcS neurons attenuated cued reward seeking while photoinhibition enhanced it (Do-Monte et al., 2017). An inhibitory role for the PVT-NAc pathway in regulating drug seeking is supported by the report that inhibition of this pathway enhanced cue-induced reinstatement of cocaine seeking
(Wunsch et al., 2017). Notably, in the latter two studies, the anterior PVT seems to be the critical area while we targeted a more posterior area of the PVT.

It is harder to reconcile our findings with the reports that the inhibition of the PVT attenuates cue-induced drug seeking. Transient pharmacological inhibition or lesioning of the PVT attenuated discriminative cue-induced reinstatement of cocaine and alcohol seeking (Matzeu et al., 2015) and context-induced reinstatement of alcohol seeking (Hamlin et al., 2009; Marchant et al., 2010). Obvious differences from our study include a different drugseeking procedure (i.e., forced abstinence vs reinstatement of extinguished behavior and exposure to discrete vs discriminative or contextual cues). Additionally, rats in the current study were trained with heroin compared with cocaine or alcohol as done in the reports by Hamlin et al. (2009) and Marchant et al. (2010), respectively. The neural circuits underlying different types of cue-induced drug-seeking procedures (Fuchs et al., 2006) and different drug categories (Badiani et al., 2011) are distinct to a large extent. Finally, the inhibition of drug seeking was demonstrated by nonselective inhibition or lesion of the whole PVT (Hamlin et al., 2009; Marchant et al., 2010; Matzeu et al., 2015). More recently, Keyes et al. (2020) have reported that silencing of the PVTNAc pathway blocked morphine-associated memory and prevented the expression of morphine conditioned place preference (CPP). However, direct comparisons with the current study are not straightforward. CPP (classical conditioning) and self-administration (instrumental conditioning) involve dissociable brain circuits and reflect different aspects of reward-associated learning (Bardo and Bevins, 2000). In addition, morphine CPP, as established in the study by Keyes et al. (2020), results in relatively limited exposure to opiates, while the rats in the current study had extensive self-administration training followed by prolonged abstinence. Both factors may result in brain adaptations that differ from the ones suggested by Keyes et al. (2020).

It is unclear how the activation of NAcS afferents from the PVT attenuates the augmentation of heroin seeking in food-restricted rats. Zhu et al. (2016) reported that chronic morphine potentiates the transmission between the PVT and the $\mathrm{D}_{2}$ receptor-expressing neuron in the NAc. Thus, activation of the PVT-NAcS pathway in heroin-abstinent rats could result in activation of the $\mathrm{D}_{2}$ receptor-expressing "indirect pathway" neurons and a punishment effect (Kravitz et al., 2012). However, this mechanism cannot explain the specific effect on heroin seeking in food-restricted rats. Earlier reports suggested that excitatory inputs from the PVT interact with acetylcholinergic $(\mathrm{ACh})$ interneurons in the NAc (Meredith and 
Wouterlood, 1990), which have a complex and potent impact on nucleus accumbens medium spiny neurons because of their extensive arborization (Contant et al., 1996). However, a more recent investigation concluded that NAc afferents from the PVT do not synapse directly onto ACh cells (Ligorio et al., 2009). Nevertheless, there is strong evidence that PVT output can modulate (perhaps indirectly) ACh release in the NAc (Kelley et al., 2005). ACh transmission in the NAc has been implicated in food and drug seeking, with increases in extracellular levels of acetylcholine associated with food satiety (Avena and Rada, 2012). Thus, activation of NAcS ACh interneurons could counteract the food restriction-induced augmentation of heroin seeking.

\section{Methodological considerations}

To validate the DREADD manipulation effect, we verified that chemogenetic manipulation of PrL-PVT and PVT-NAc pathways alters neural activity, indicating that the lack of effect following manipulations of the PrL-PVT and PVT-NAcC pathways was unlikely because of a lack of DREADD efficacy. Moreover, only rats with strong DREADD expression in both the cell body and target terminal regions verified by robust mCherry expression were included in the final analyses. Last, because nonspecific effects for $\mathrm{CNO}$ administration have been reported (Gomez et al., 2017), we verified that in rats expressing only mCherry in the PVT-NAcS pathway the infusion of CNO did not alter the augmentation of heroin seeking induced by chronic food restriction.

\section{Conclusion}

Our findings extend current knowledge about the role of the PVT and its projections in drug seeking. Importantly, a role for the PVT-NAcS pathway in heroin seeking has been demonstrated only in food-restricted rats. Our findings support the idea that the PVT is recruited under challenging conditions. For example (Choi et al., 2019) reported that the PVT is involved in behavioral control only during conflict. The exact mechanisms underlying this effect remain elusive.

\section{References}

Anderson RI, Bush PC, Spear LP (2013) Environmental manipulations alter age differences in attribution of incentive salience to reward-paired cues. Behav Brain Res 257:83-89.

Avena NM, Rada PV (2012) Cholinergic modulation of food and drug satiety and withdrawal. Physiol Behav 106:332-336.

Badiani A, Belin D, Epstein D, Calu D, Shaham Y (2011) Opiate versus psychostimulant addiction: the differences do matter. Nat Rev Neurosci 12:685-700.

Bardo MT, Bevins RA (2000) Conditioned place preference: what does it add to our preclinical understanding of drug reward. Psychopharmacology (Berl) 153:31-43.

Campus P, Covelo IR, Kim Y, Parsegian A, Kuhn BN, Lopez SA, Neumaier JF, Ferguson SM, Solberg Woods LC, Sarter M, Flagel SB (2019) The paraventricular thalamus is a critical mediator of top-down control of cue-motivated behavior. Elife 8:e49041.

Carroll ME, Meisch RA (1984) Increased drug-reinforced behavior due to food deprivation. In: Advances in behavioral pharmacology (Thompson T, Dews PB, Barrett JE eds), Ed 4, pp 47-88. Orlando: Academic.

Cheskin LJ, Hess JM, Henningfield J, Gorelick DA (2005) Calorie restriction increases cigarette use in adult smokers. Psychopharmacology 179:430436.

Childress AR, Hole AV, Ehrman RN, Robbins SJ, McLellan AT, O’Brien CP (1993) Cue reactivity and cue reactivity interventions in drug dependence. NIDA Res Monogr 137:73-95.

Chisholm A, Iannuzzi J, Rizzo D, Gonzalez N, Fortin É, Bumbu A, Batallán Burrowes AA, Chapman CA, Shalev U (2020) The role of the paraventricular nucleus of the thalamus in the augmentation of heroin seeking induced by chronic food restriction. Addict Biol 25:e12708.

Choi EA, Jean-Richard-Dit-Bressel P, Clifford CWG, McNally GP (2019) Paraventricular thalamus controls behavior during motivational conflict. J Neurosci 39:4945-4958.

Contant C, Umbriaco D, Garcia S, Watkins KC, Descarries L (1996) Ultrastructural characterization of the acetylcholine innervation in adult rat neostriatum. Neuroscience 71:937-947.

D'Cunha TM, Sedki F, Macri J, Casola C, Shalev U (2013) The effects of chronic food restriction on cue-induced heroin seeking in abstinent male rats. Psychopharmacology (Berl) 225:241-250.

D'Cunha TM, Daoud E, Rizzo D, Bishop AB, Russo M, Mourra G, Hamel L, Sedki F, Shalev U (2017) Augmentation of heroin seeking following chronic food restriction in the rat: differential role for dopamine transmission in the nucleus accumbens shell and core. Neuropsychopharmacology 42:1136-1145

D'Cunha TM, Chisholm A, Hryhorczuk C, Fulton S, Shalev U (2020) A role for leptin and ghrelin in the augmentation of heroin seeking induced by chronic food restriction. Psychopharmacology 237:787-800.

De Wit H (1996) Priming effects with drugs and other reinforcers. Exp Clin Psychopharmacol 4:5-10.

Do-Monte FH, Minier-Toribio A, Quiñones-Laracuente K, Medina-Colón EM, Quirk GJ (2017) Thalamic regulation of sucrose seeking during unexpected reward omission. Neuron 94:388-400.e4.

Dong X, Li S, Kirouac GJ (2017) Collateralization of projections from the paraventricular nucleus of the thalamus to the nucleus accumbens, bed nucleus of the stria terminalis, and central nucleus of the amygdala. Brain Struct Funct 222:3927-3943.

Franklin JC, Schiele BC, Brozek J, Keys A (1948) Observations on human behavior in experimental semistarvation and rehabilitation. J Clin Psychol 4:28-45.

Fuchs RA, Branham RK, See RE (2006) Different neural substrates mediate cocaine seeking after abstinence versus extinction training: a critical role for the dorsolateral caudate-putamen. J Neurosci 26:3584-3588.

Giannotti G, Barry SM, Siemsen BM, Peters J, McGinty JF (2018) Divergent prelimbic cortical pathways interact with $\mathrm{BDNF}$ to regulate cocaine-seeking. J Neurosci 38:8956-8966.

Gomez JL, Bonaventura J, Lesniak W, Mathews WB, Sysa-Shah P, Rodriguez LA, Ellis RJ, Richie CT, Harvey BK, Dannals RF, Pomper MG, Bonci A, Michaelides M (2017) Chemogenetics revealed: DREADD occupancy and activation via converted clozapine. Science 357:503-507.

Hall SM, Tunstall CD, Vila KL, Duffy J (1992) Weight gain prevention and smoking cessation: cautionary findings. Am J Public Health 82:799-803.

Hamlin AS, Clemens KJ, Choi EA, McNally GP (2009) Paraventricular thalamus mediates context-induced reinstatement (renewal) of extinguished reward seeking. Eur J Neurosci 29:802-812.

Kelley AE, Baldo BA, Pratt WE (2005) A proposed hypothalamic-thalamicstriatal axis for the integration of energy balance, arousal, and food reward. J Comp Neurol 493:72-85.

Keyes PC, Adams EL, Chen Z, Bi L, Nachtrab G, Wang VJ, Tessier-Lavigne M, Zhu Y, Chen X (2020) Orchestrating opiate-associated memories in thalamic circuits. Neuron 107:1113-1123.e4.

Kirouac GJ (2015) Placing the paraventricular nucleus of the thalamus within the brain circuits that control behavior. Neurosci Biobehav Rev 56:315329.

Krahn D, Kurth C, Demitrack M, Drewnowski A (1992) The relationship of dieting severity and bulimic behaviors to alcohol and other drug use in young women. J Subst Abuse 4:341-353.

Kravitz AV, Tye LD, Kreitzer AC (2012) Distinct roles for direct and indirect pathway striatal neurons in reinforcement. Nat Neurosci 15:816-818.

Kuhn BN, Klumpner MS, Covelo IR, Campus P, Flagel SB (2018) Transient inactivation of the paraventricular nucleus of the thalamus enhances cue-induced reinstatement in goal-trackers, but not sign-trackers. Psychopharmacology 235:999-1014.

Li S, Kirouac GJ (2012) Sources of inputs to the anterior and posterior aspects of the paraventricular nucleus of the thalamus. Brain Struct Funct 217:257-273.

Ligorio M, Descarries L, Warren RA (2009) Cholinergic innervation and thalamic input in rat nucleus accumbens. J Chem Neuroanat 37:33-45.

Marchant NJ, Furlong TM, McNally GP (2010) Medial dorsal hypothalamus mediates the inhibition of reward seeking after extinction. J Neurosci 30:14102-14115. 
Matzeu A, Zamora-Martinez ER, Martin-Fardon R (2014) The paraventricular nucleus of the thalamus is recruited by both natural rewards and drugs of abuse: recent evidence of a pivotal role for orexin/hypocretin signaling in this thalamic nucleus in drug-seeking behavior. Front Behav Neurosci $8: 117$.

Matzeu A, Weiss F, Martin-Fardon R (2015) Transient inactivation of the posterior paraventricular nucleus of the thalamus blocks cocaine-seeking behavior. Neurosci Lett 608:34-39.

Meredith GE, Wouterlood FG (1990) Hippocampal and midline thalamic fibers and terminals in relation to the choline acetyltransferase-immunoreactive neurons in nucleus accumbens of the rat: a light and electron microscopic study. J Comp Neurol 296:204-221.

Millan EZ, Ong Z, McNally GP (2017) Paraventricular thalamus: gateway to feeding, appetitive motivation, and drug addiction. Prog Brain Res 235:113-137.

O’Brien CP (1997) A range of research-based pharmacotherapies for addiction. Science 278:66-70.

Otis JM, Namboodiri VM, Matan AM, Voets ES, Mohorn EP, Kosyk O, McHenry JA, Robinson JE, Resendez SL, Rossi MA, Stuber GD (2017) Prefrontal cortex output circuits guide reward seeking through divergent cue encoding. Nature 543:103-107.

Otis JM, Zhu M, Namboodiri VMK, Cook CA, Kosyk O, Matan AM, Ying R, Hashikawa Y, Hashikawa K, Trujillo-Pisanty I, Guo J, Ung RL, Rodriguez-Romaguera J, Anton ES, Stuber GD (2019) Paraventricular thalamus projection neurons integrate cortical and hypothalamic signals for cue-reward processing. Neuron 103:423-431.e4.

Paxinos G, Watson C (2005) The rat brain in stereotaxic coordinates, Ed 5. San Diego: Elsevier Academic Press.

Pirie PL, McBride CM, Hellerstedt W, Jeffery RW, Hatsukami D, Allen S, Lando H (1992) Smoking cessation in women concerned about weight. Am J Public Health 82:1238-1243.
Reiner DJ, Fredriksson I, Lofaro OM, Bossert JM, Shaham Y (2019) Relapse to opioid seeking in rat models: behavior, pharmacology and circuits. Neuropsychopharmacology 44:465-477.

Sedki F, Abbas Z, Angelis S, Martin J, D'Cunha T, Shalev U (2013) Is it stress? The role of stress related systems in chronic food restriction-induced augmentation of heroin seeking in the rat. Front Neurosci 7:98.

Sedki F, Gardner Gregory J, Luminare A, D'Cunha TM, Shalev U (2015) Food restriction-induced augmentation of heroin seeking in female rats: manipulations of ovarian hormones. Psychopharmacology (Berl) 232:3773-3782.

Shalev U (2012) Chronic food restriction augments the reinstatement of extinguished heroin-seeking behavior in rats. Addict Biol 17:691-693.

Shalev U, Yap J, Shaham Y (2001) Leptin attenuates acute food deprivationinduced relapse to heroin seeking. J Neurosci 21:RC129-RC129.

Shalev U, Marinelli M, Baumann MH, Piazza PV, Shaham Y (2003) The role of corticosterone in food deprivation-induced reinstatement of cocaine seeking in the rat. Psychopharmacology (Berl) 168:170-176.

Sinha R (2001) How does stress increase risk of drug abuse and relapse. Psychopharmacology (Berl) 158:343-359.

Tang YY, Posner MI, Rothbart MK, Volkow ND (2015) Circuitry of self-control and its role in reducing addiction. Trends Cogn Sci 19:439-444.

Wunsch AM, Yager LM, Donckels EA, Le CT, Neumaier JF, Ferguson SM (2017) Chemogenetic inhibition reveals midline thalamic nuclei and thalamo-accumbens projections mediate cocaine-seeking in rats. Eur J Neurosci 46:1850-1862

Zhang X, van den Pol AN (2017) Rapid binge-like eating and body weight gain driven by zona incerta GABA neuron activation. Science 356:853859.

Zhou K, Zhu Y (2019) The paraventricular thalamic nucleus: a key hub of neural circuits underlying drug addiction. Pharmacol Res 142: 70-76.

Zhu Y, Wienecke CF, Nachtrab G, Chen X (2016) A thalamic input to the nucleus accumbens mediates opiate dependence. Nature 530:219-222. 